\title{
DE MYTHE VAN DEN BERG MANDARA IN DE JAVAANSCHE LETTERKUNDE.
}

DOOR

DR. H. H. JUYNBOLL.

In de inleiding van mịnn proefschrift "Drie boeken van het OudJavaansche Mahâbhârata" enz. heb ik (pag. 6) de aandacht gevestigd op het feit, dat de mythe van den berg Mandara, die zoowel in de Oudjav. cosmogonie Tantu Panggĕlaran als in de Nieuwjav. Manik Maya verhaald wordt, sporen draagt van ontleend te zijn aan het Ádiparwa van het Mahâbhârata. Eenige maanden nadat ik dit geschreven had, ontving ik van dr. Brandes uit Batavia een afdruk van de notulen van het Bataviaasch Genootschap, waarin dat gedeelte van het Oudjavaansche Ādiparwa, dat aan deze mythe tot grondslag gestrekt heeft, uitgegeven is. Naar aanleiding hiervan kom $\mathrm{ik}$ nog eens op dit onderwerp terug, om nader aan te toonen, in welk opzicht de verhalen in het Ádiparwa, den Tantu Panggĕlaran en de Manik Maya overeenstemmen. Dr. Brandes heeft wel is waar een gedeelte van den Sanskrittekst en een uittreksel uit Pratap Chandra Roy's Engelsche vertaling van het Mahâbhârata op den Oudjav. tekst laten volgen, maar de Kawitekst is geenszins eene vertaling van den Sanskrittekst en de Engelsche vertaling is zeer vrij. Bovendien is het Oudjav. woordenboek nog niet in druk verschenen, daarom schijnt het mij niet overbodig toe, hier nog eene zooveel mogelijk letterlijke vertaling van den door dr. Brandes uitgegevenen Oudjav. tekst te geven, waarbij ik tevens eenige aanteekeningen en andere lezingen, die ik aan het Leidsche HS. 3127 en het HS. van prof. Kern ontleend heb, zal voegen. De vertaling luidt aldus:

Wij zullen het verhaal een oogenblik ${ }^{1}$ laten rusten en spreken ${ }^{2}$

1 Sakarěng beteekent hetzelfde als het Sund. saköḍong. Zie prof. Kern's Kawistudiën p. $80-81$ en mijn proefschrift pag. 181. In een HS. van het O. Jav. Râmâyana met Balin. interlineaire vertaling in het bezit van prof. Kern, die het mij welwillend ter lezing afstond, verklaart de Balineesche glossaar (fol. 193) $\mathrm{s}$ a k a r ěn g door het Balin. k ěs ěp.

${ }^{2}$ Over tucapa zie men prof. Kern's verhandeling over Oudjav. absolutieven in deze Bijdragen, 5 e volgr. IV p. 53 (p. 10 van den overdruk). 
over het karnen van den oceaan, de oorzaak van het ontstaan van Uccaihçrawas, die de aanleiding was, dat Winatâ de slavin van Kadrû werd; de toedracht dezer zaak was aldus: Alle goden beraadslaagden gezamenlịk op den top van den berg Mahâmeru: de zaak, waarover zij beraadslaagden, was de wijze, waarop zij den onsterfelijkheidsdrank zouden verkrijgen; alle daitya's en dânawa's namen deel aan de beraadslaging, daar zijj allen den nectar begeerden; bij de beraadslaging der goden en daemonen nu sprak Nârâyaṇa: "Als gij den nectar begeert, o goden, utsâhakâryyapị̂itậ ' ', moet gij niet nalaten, $u$ in te spannen, om de Melkzee te karnen, want deze is als het ware te beschouwen als de plaats van den nectar; ten einde den nectar te verkrijgen, moet gij alles in het werk stellen, om te karnen; dit moet gij doen." Zoo sprak de heilige Nârâyaṇa: dit werd goedgevonden door de schaar der goden en daemonen; zij allen nu gingen naar de Melkzee. $\mathrm{Nu}$ was er een berg, Mandara genaamd, een berg van Jambudwîpa ${ }^{2}$, een land, gelegen aan de kust van de Melkzee; zijne hoogte was, ekâdaçasahasrâni, elfduizend yojana's, adhobhûmeḥ sahasrâṇi ${ }^{3}$, maar het strand 1000 yojana's: zoo groot was de afmeting van de breedte ${ }^{4}$ van den berg Mandara, deze werd getrokken ${ }^{5}$ door god Anantabhoga en voortgesleept met al wat er op was: hij liet hem vallen in de Melkzee, om te dienen tot ${ }^{6}$ het karnen van de zee; de goden spraken tot den Oceaan: "Wees zoo goed, Oceaan, u niet te verzetten tegen het verdragen van de omhelzing van het eiland, als werkelijk de nectar uit de Melkzee komt, zullen de drie werelden uitermate verheugd zijn en zult gij zeer goddelijk zijn, daar gij aan alle goden vreugde kunt schenken." Zoo spraken de goden; de Oceaan

1 Het Bat. HS., dat ik C zal noemen, leest utsangkâryapiḍitah, het Leidsche (B) utsâhakay yapiḍitaḥ, dat van prof. Kern (A) utsâhangkâryyapiḍitaḥ. De ware lezing volgt uit den samenhang en beteekent: door inspanning gekweld.

${ }^{2}$ B leest Sanggadwipa, A en C Çangkâdwipa. De ware lezing blijkt uit den Tantu. In de Manik Maya is de naam tot Jamur Dipa verbasterd.

3 B leest ekadaçahasraṇi adohbhumeḥ sahasrâni, C ekadaçasahasrañi adobhùmeh sahaçraṇi sahaçraṇi. De ware lezing blijkt uit çloka 1114 van den Skr. tekst van het Ādiparwa.

${ }^{4} \mathrm{Lw}$ â. Zie over dit woord mijn proefschrift p. 184, waar men de woorden «Bul. louag» gelieve te veranderen in "Bul. luag.» Vgl. ook Sumb. měloa «ruim». De Balin. glossator van het 0. J. Râm. (fol. a, 69) verklaart 1 wa ḋoor het Balin. linggah. Zoo ook m a l wâ (fol. 340). A l wa â vertolkt hij (fol. 133) door het Balin. $1 \mathrm{umbang}$.

5 Dinawut. Zoo lezen $A$ en $C$, doch B sinawut.

${ }^{6}$ Mapakna is verwant met het Sund. pikön. Zie mijn Proefschrift p. 212. 
was gewillig. $\mathrm{Nu}$ was er een zekere Akûpâra ${ }^{1}$, kûrmarâja, de koning der schildpadden, eene incarnatie van god Wiṣnu volgens het oude verhaal: deze nu kreeg bevel, om het lichaam van den berg Mandara te dragen en te strekken tot grondslag van het ondereinde ${ }^{2}$ van den berg, opdat hij niet naar beneden zou zakken; god Bâsuki strekte tot touw en wikkelde zich om de zijde van den berg, en God Indra steeg op den top, om er bovenop te zitten, opdat hij bij het draaien niet naar boven zou gaan; toen dit werk volbracht was, toen gingen de goden en daemonen trekken aan Bâsuki, als ware hij het touw van den berg Mandara; alle goden nu waren geplaatst bij de staart van den slang en de schaar der daemonen bij de kop van den slang; zij trokken er aan. Toen kwam er een vurig vergif uit den adem van den slang, hetgeen het moeielijk ${ }^{3}$ maakte voor de daemonen, maar zonder te wijken vatten zij hem aan ${ }^{4}$, opdat de nectar er uit zou komen; allen schreeuwden en juichten en waren verheugd. Daarbij kwam het geluid van de zee als het gerommel 5 der donderwolken, evenals het geluid van de wolken in den tijd van den wereldondergang; het was niet om aan te hooren voor hen; wegens den langen duur van het ronddraaien van den berg Mandara, raakten de steenen in verwarring en werden zij weggeslingerd 6 en stortten de boomen omver, gescheiden van hunne makkers, teṣậ sanggharṣaṇe ${ }^{7}$. Toen kwam er vuur uit, dat uitermate schitterde en de bosschen verbrandde met alle dieren, vooreerst gazellen, leeuwen, everzwijnen en rhinocerossen; zij vluchtten zonder te weten waarheen. Evenzoo

1 A leest çakupa, B en C A kupa. De ware lezing blijkt uit çloka 1122.

2 Bungkah beteekent in het Mal. "brok, blok»; vgl. het Jav. bongk ot. Het woord komt ook voor in den Tantu Panggělaran p. 9: Sira ta bungkah enz.

s Durlabha, eigenlijk «moeielijk te verkrijgen». Zie mijn Proefschrift p. 164.

4 Voor surudanyârâmbananikâ, zooals C leest, leze men surud denyârambhana nikâ, zooals $A$ en $B$ hebben. Pangârambhana beteekent: het ondernemen van iets, bijv. Pangârambhana nira yajnasarppa, $\bar{A}$ dip. 42.

${ }^{5} \mathrm{G}$ ěr $\mathrm{r} \mathrm{h}$ beteekent "gebulder, donderend gerommel», bijv. Ādip. 159: Kilat awilět saha gěrěh agěnturan: Udyogap. a. 73 staat het bij jı mùta, een synoniem van puskarâwarttaka. Dit laatste woord is in B goed gespeld. A leest puṣârawarttaka, C puskârawartakâ.

6 Kahabalang komt meermalen in het Mahabh. voor, bijv. Udyogap. 8, Ādip. 39 : Katup, kahabalang, kasusang. kawalik. Arj. Wiw. 37 : Kabwang dhwasta kahabalang. Ook in abalangakĕn en angabalang akěn komen voor Ädip. 79. Vgl. N.Jav.xnñ

7 A leest pagaçanigharşanaa, B en C paçanigharşañe. Mijne lezing steunt op çloka 1134: Tesậ sanggharsaja ̣̂ câgnir arcibhị̣ prajwala muhuh.

6e Volgr. I. 
werden de visschen in de zee uitgeworpen en weggeslingerd en naar de Zoutzee gevoerd, door de snelheid van den wind, die floot ${ }^{1}$, zoo snel als de wind was het karnen van de Zoutzee en het ronddraaien van den berg Mandara; god Waruna, die werd met den diskus geschoten door god Wiṣnu; hịj trachtte zich te verschuilen en vluchtte naar de ouderwereld, duizelig door het karnen van de Melkzee, deze werd smedig, alsof zij gezoden was, gaar gekookt door de hitte van het vuur, dat straalde uit de zijde van den berg Mandara, en de straal van het vergif, dat uit den bek van Wâsuki kwam; toen bedacht god Indra, dat de goden en daemonen zouden verbranden door het vuur, terwịl zij zich vermoeiden met het karnen; hij riep de wolken op ${ }^{2}$. Deze kwamen van de tien windstreken; de berg en de zee werden bedekt door de wolken, alsof zij omhuld waren ${ }^{3}$, met hun weerlicht en donder; deze liet hij als regen neervallen, waardoor ten slotte het vuur uitdoofde, maar het vet ${ }^{4}$ van alle dieren, die door het vuur verbrand waren, on niet te spreken van het sap ${ }^{5}$ der boomen; dit alles stroomde en droop in de Zoutzee en deze werd hoe langer hoe smediger; de goden en daemonen lieten het doorzijpelen en persten het bij het karnen; hun werd kracht verleend door god Wịnnu, tatạ̣ ksîrâd abhûd $\mathrm{ghrtam}{ }^{6}$ ten slotte kwam er olie nit de melk, evenzoo als vroeger de Ardhacandra; daarop volgde de godin Çrî, toen het juweel Kaustubha, dewâ yatas tato jagmuḥ ${ }^{7}$, en het viel alleen

$1 \mathrm{Agh}$ âsa beteekent «een schurend geluid maken, piepen», bijv. B. Y. 315: amuluh aghâsa, 450: Aghàsâpagut sěk tațitnya. A. W. 44: Wuluh aghâsa (Bal. vert.

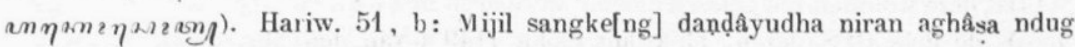
amupuh. Ook paghâsa komt voor, bijv. Smarad. 12, b: Paghâsa ning wungka] awantah atri. Misschien is het eene verbastering van Skr. gharsa. Ik dank deze plaatsen aan prof. Kern. Dr. Brandes vat blijkbaar y a nag ha sa als eene aanhaling uit den Skr. tekst op, daar het cursief gedrukt is.

2 Inâradhana komt ook voor Udyogap 35. De stam ârâdhana beteekent «oproeping om te verschijnen», bijv. Udyogap. 96 en Ādip. 99. Ook de vormen u mârâdhana, Ādip. 63 en mangârâdhana, Ādip. 159 komen voor.

s Sumahab. Deze beteekenis heeft sahab ook in de O.J. oorkonde van Caka 782, uitgegeven door prof. Kern (Med. Kon. Akad. v. Wet. 3e Reeks X, N. V a).

4 Wuduk komt ook voor Ādip. a, 159: Umis ta wudukuyâměluran.

${ }^{5}$ Gětih heeft deze beteekenis ook in het Pausyacarita (Over de 0 . J. vertaling van 't Mahabh. p. 13): Amangan ta sira gtih ing rwân ing wadurï. Evenzoo Arj. Wiw. 306: Gětih ing kukap. De laatste plaats dank ik aan prof. Kern.

6 Deze woorden staan evenzoo in çlok 1139 van den Sanskrittekst.

7 A en C lezen dewoyathatatwajagmuḥ, B deyvyathatwajagmuh. De ware lezing blijht uit çloka 1148: Yato dewâs tato jagmur. 
aan de goden ten deel, niet aan de daemonen, Dhanw antaris tato dewaḥ ${ }^{1}$, ten slotte kwam Dhanwantari te voorschịnn en hịj droeg de witte Kamaṇ̦alu, waarin zich de nectar bevond; deze werd genomen door de daemonen, mamedam iti jalpatâm ${ }^{2}$, "laat dit ons deel zijn", zoo waren de woorden, die zij spraken; nadat nu de nectar er uitgekomen was, brachten zij den berg Mandara terug naar zịne vroegere plaats in Jambudwîpa; de goden nu rustten.

Tot zoover loopt het gedeelte, dat door dr. Brandes uitgegeven is. Ik geef hier nog een vervolg van den O. J tekst, waarbij ik het HS. van prof. Kern, dat veel beter is dan het Leidsche ${ }^{3}$, tot grondslag genomen heb. Onmiddellijk op de woorden "marâryan ta sang watěk dewatâ" volgt (A fol. 31 , overeenkomende met B. a, 36): Mangangěnaugĕn 4 ta bhațâra Wiṣnu i mârgga ning [mayun] (a)mṛta 5 kâlapa ${ }^{6}$ de nira, magawe ta sira mâya strîrûpa ${ }^{7}$, anawady ân ggawayawâ ${ }^{\mathbf{3}}$, paripûrṇna ring hayu, ḍatěng manunggangï daityarûpa, sarwwe tadgat a mâna sâh ${ }^{9}$, kapwa kakarṣaṇa ya kating(h)alan, harṣa ta manah nikang daitya tumon ing strî, winehaknikâng amṛta ring 10 Kamaṇạalu pangkunĕn ing strîmâya, lunghâ 11 tang strîmâya mawa ng amṛta, maluy Wiṣụurûpa nira, tuminghal ikang daitya krodha ta ya, kapwa sangrabdhâ sangkĕp ing saũjatanya, hanan musala gadâ 12 tomara sinambutnya manututi sang hyang

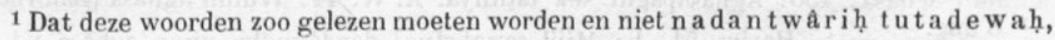
zooals de drie HSS. lezen, blijkt uit çloka 1149 a van den Skr. tekst.

2 A leest mamedam ati jampatih, B mámeda pati jampatih̆, C mamedam atimpatih. De ware lezing blijkt uit çloka 1150 b van den Skr. tekst.

3 Zie Vreede, Catalogus ler Jav. en Mad. HSS. p. 387 en mijn Proefschrift p. 4.

4 B mangěnangěn. Wijlen Dr. v. d. Tuuk deelde mij mede, dat kâlěngěn (Ā çrarnap. a , 3, 13 Mausalap. 38 enz.) eene verkorte Bal. spelling is voor kângěnangěn. Zie verder mijn Proefschrift pag. 154.

5 B ning amṛta.

6 B kala.

7 B Çrirupa.

8 A anawâryyanggâwayawa, B aniwayyângawayawa. Het ontbreekt in den Skr. tekst.

9 A sarwwakadgattamânataḥ, B sarwwahanggatwa manakah. Zie çloka 1157 ran den Skr. tekst.

10 B tumun i Çri wiwinehaknikâ tamṛta ri.

11 B Srimâya lungha.

12 B gadam. 
Wiṣnu, kawnangan 1 ta sira ḍatĕng sarwwadewata makâdi hyang Brahmâ, sang hyang l̂çwara, tumulung i sang hyang Wiṣnu , matangkĕp ikang ${ }^{2}$ prang, paprangan ira ri samîpa ning Lawan[a mb]ârṇ̣awa, ikang Jambudwîpa ${ }^{3}$ pinggir ing Lawa(na)sâgara , tatan hana kasor ing laga ${ }^{4}$, kapwâgalak paḍa çakti, kapwa wâni marangkit ${ }^{5}$ marurĕk arok silih usî, tangeh ikang ${ }^{6}$ prang hiḍe bhațâra Wiṣnu, matangyan inangĕnàngĕn ira cakra nira, $[$ pana(h) ngaran ing daitya], kṣaṇâd wicintitamâtro gatạ̣ ${ }^{7}$, sakarĕng inadhișthânâ, mijil taya sakeng âkâça, jw a litahu tâçanaprabham ${ }^{\mathbf{8}}$, kadi teja ning apuy dumilah tejanya ya tikâ cinakrâkĕn de bhațâra Wiṣnu ri detya, pgat gulunya, ça ta s a ha s ro m ṛta ḥ ${ }^{9}$, inatus iwu kweh(nya) pjah, linud ta ya dening Nârâyanâstra , muwah pinanah tayeng niçita ${ }^{10}$ çara, mangkin ta yâlayu tan (h)anânolih, ikang çeșa ning mâti, ya tikâ sumilěm ing tasik, mahĕthötan ing pâtâla, alah tang daitaya rákṣasa, râh nikang ${ }^{11}$ samangkana, ya tika matmahan lwah, umili 12 tkeng Lawanasamudra, âditye lo hitarakte ${ }^{13}$, abâng ta sang hyang Aditya kasĕnwan bângnya, mangkana ta wangkaynya, a dṛiṇâm iwa kûṭ̂ni dhâtu raktâni çerate ${ }^{14}$, kadi pucak ning wukir abâng dening d(h)âtu, mangkana ta lwir ni wangkaynya, gumuling ing prthwitala.

Sâmpun ikang daitya dânawâlah, mulih ta bhațâra Wiṣnu makering dewasanggha, makolih rikang âmṛta, prápteng Wiṣnuloka sira, ininum nira tekang âmrita, ya ta hetu nikang amara ${ }^{15}$ tan

1 B kawnanga.

2 B ing.

s A en B Sangkadwipa.

- B alaga.

s B wani mangkět.

6 B nira.

7 A en B ksanaharicintitamatra gatih. Zie echter çloka 1178 van den Skr. tekst.

8 A jwalitahutaçanasamapranaṃ, B lwalitao. Zie çloka 1179.

- A çatasahasraḥ mârtaḥ, B çâtasahasra ș̣htaḥ. Vgl. çloka 1182 : sahasraço.

10 B nisita nira.

11 B ning.

12 B umilit.

18 Zie çloka 1173 b: Anyonyam chindatạ çastrair âditye lohit A y a ti.

14 A adrim iwâ piçawâni câturaktâni çonite, B ${ }^{\circ}$ dhâturâktâni s o nite. De ware lezing blijkt uit çloka 1172 b van den Skr. tekst.

15 B om. nikang amara. 
kneng pati, mangrĕngö tang dânawa ' anak sang Wipracitti ${ }^{2}$ matmu tangan lâwan sang ${ }^{3}$ Singhikâ, ya tikâ dewatârûpa ${ }^{4}$, milw anginum ${ }^{5}$ amrita, wruh pwa ya ${ }^{6}$ sang hyang Candrâditya yan dânawa ${ }^{7}$, majar ta sire ${ }^{8}$ bhațîra Wị̣nu, sdĕng ning âmṛta haneng gulunya, cinakra ta ya, pgat gulunya, tibâ ta lawayanya (l. awayawanya) ri(ng) lmah, kadi tibâ ${ }^{9}$ ni parwwataçik(h)ara, lindu lang prị(h)iwî 10 molah deni bwat 11 ni(ng) kawandhanya, ndân çirahnya mĕsat 12 ring âkâça deni[ng] kapawitran ning amṛta, anghing çarîranya juga pjah, apan tan katkân âmṛta, sangka yan lara ng ${ }^{13}$ amběknya, an winarahakěn de ${ }^{14}$ hyang Candrâditya ri bhațâra Wiṣnu, bhakșati rawicandrau ${ }^{15}$, ya ta mantangyan ta ya krodha ri sang hyang Candrâditya, umangan sirângkĕn parwa kâla ${ }^{16}$, nâhan ta krama ning amṛtamanthana $\mathbf{1 7}$.

De vertaling van dit gedeelte luidt aldus:

God Wișnu dacht na over de wijze, waarop hij den nectar zou verkrijgen; hij maakte een beeld met het uiterlijk van eene vrouw, an awadyânggawayawâ, volmaakt schoon; zij kwam in de gedaante van eene daityâ, sarwwe tadgatamânasâh, allen waren verrukt ${ }^{18}$ bij het gezicht; de daemonen waren verheugd, toen zij

1 B marĕngě ta dhânawâ.

2 A Wipracinti, B Pracinti. De lezing Wipracitta in de Calc. uitgave is foutief.

3 B si.

$4 \mathrm{~B}$ dewarupa.

$5 \mathrm{~B}$ anginem.

6 B om. y a.

7 B dandatha.

8 B om. sire.

$9 \mathrm{~B}$ ba.

$10 \mathrm{~B}$ teng apritiwa.

$11 \mathrm{~B}$ dening bwa.

12 B siramsat.

13 B dharany.

14 B sang.

15 A bhâksaneng warawicandraḥ, B bhaissaneng rawicandraḥ. Zie çloka 1166 b van den Skr. tekst.

16 B sirân angkĕn purnnamamakâla, A sira ngkẽn pùrṇnakâla.

17 A en B omangkana.

18 Kâkarșa a "aangetrokken, verrukt, bekoord», van Skr. âkarșana komt

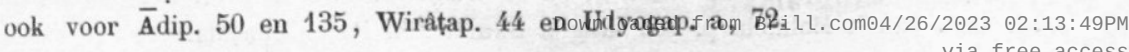


de vrouw zagen; zịj gaven den nectar in de Kamaṇạalu aari het vrouwenbeeld: om op den schoot te houden; toen verdween het v rouwenbeeld met den nectar en nam weer de gedaante van Wiṣnu aan. Toen de daemonen dit zagen, werden zịj vertoornd; allen vatten bunne wapenen op ${ }^{1}$. Sommigen grepen humne knotsen en werpspiesen en vervolgden god Wiṣnu; hịj werd bereikt door alle goden; vooreerst god Brahmâ en god Îçwara, die god Wiṣnu te hulp kwamen. Zij raakten slaags; hun slagveld was in de nabijheid van de Zoutzee, in Jambudwîpa, aan den oever van de Zoutzee; geen van hen werd overwonnen in den strijd. Allen waren even verwoed en krachtig; allen waren even dapper. Zịj sloegen elkaar en zij kwamen dichtbijeen en raakten vermengd ${ }^{2}$ en zịj vervolgden elkaar; god Wiṣnu begreep, dat de strijd nog lang kon duren. Daarom dacht hij aan zịnn werpschịf, kṣaṇ̂ad wicintitamâtro gataḥ, in een oogenblik riep hij hem op; hij kwam uit den hemel, jwalitahutâçanaprabham, zijn glans schitterde als de glans van het vuur; hiermede schoot god Wiṣnu op de daemonen en brak humne halzen, çatasahasro mṛtaḥ, honderdduizend sneuvelden, meegevoerd door het wapen van Nârâyana en getroffen door de scherpe pijlen; toen vluchtten zij zonder om te kijken. Zij, die aan den dood ontkomen waren, doken in de zee, eene schuilplaats zoekende ${ }^{3}$ in de onderwereld; de daitya's en râkṣasa's werden overwonnen. Al hun bloed werd tot een rivier, die in de Zoutzee stroomde, âditye lohitarakte, de zon werd rood, verlicht door den rooden gloed ervan; de lijken waren als, a drînâm iwa kûṭ̂ni dhâturaktâni çerate, als bergtoppen, die rood zijn door metalen, zoo zagen de lijken er uit, die op den grond lagen.

1 Sangrabdha, part. perf. pass. van sa mprambh (Skr.) «aanvatten» komt in het zelfde verband voor $\bar{A}$ dip. 39: kapwa ta s. ri pasangkĕpan ikang sañjata.

2 A rok beteekent "raakte vermengd, kwam dooreen", zooals blijkt uit $\bar{A}$ dip. 67: Arok tikang wastra kawawa dening halisyus magöng. Daar is het eene vertaling van Skr. wyatimiçra. De vorm marok komt o. a. voor Swargârohanap. a, 94. Ook rangkit heeft hier eene ruimere beteekenis dan in 't N. Jav. Zoo ook B. K. 187: Enak i rangkit ing prang awilět. 217: Humung marangkit alaga. Hariw. 54, d: Silih daṇ̦a ta sira, wěkasan lot arangkit silih kol. De drie laatste plaatsen dank ik aan prof. Kern.

3 Mahĕthötan "zich verschuilende» komt ook voor Ādip. 90. Verder komen van den höt nog deze vormen in het $\bar{A}$ dip. voor: pahöthötan "schuilplaats» Ādip. 163, manghötakěn “willende verbergen», Ädip. 90 , pahĕ thětana a(een hol) warin een schuilplaats gezocht worde», Ädip. 36 , h u möt "zich verschuilende», Ādip. 31 en Râm. a, 92 en hum ětak ěn in prof. Kern's Over de 0. J. vert. van 't Mahâbh. p. 16: lunghâ humētakěn ikang kuṇạala. 
Nadat de daitya's en dânawa's overwonnen waren, keerde god Wiṣnu met de schaar der goden terug, in het bezit van 1 den nectar; in den hemel van Wiṣnu gekomen zijnde, dronken zij den nectar, waardoor de goden onsterfelijk werden; toen hoorden zij, dat een daemon, de zoon van Wipracitti ${ }^{2}$, gehuwd met Singhikâ, in de gedaante van een god mede van den nectar gedronken had, doch de Zon en de Maan wisten, dat hij een daemon was, zij vertelden het aan god Wiṣnu, terwijl de nectar juist in zijn keel was. Hij schoot hem met ziju werpschijf en brak zijn keel; zijn lichaam ${ }^{3}$ viel op den grond als een bergtop. De aarde beefde en kwam in beweging door de zwaarte van zijn lijk; zijn hoofd vloog de lucht in door de reinigende kracht van den nectar, maar zijn lichaam stierf, omdat het niet bereikt was door den nectar; uit wrok jegens Zon en Maan, omdat zij het verteld hadden aan god Wiṣnu, bhakṣati rawicandrau, daarom is hij vertoornd op Zon en Maan en wil hij hen telkens ${ }^{4}$ bij iedere conjunctie en oppositie ${ }^{5}$ verslinden. Zoo is het verhaal van het karnen, om den nectar te verk rijgen ${ }^{6}$.

Thans ga ik over tot den Tantu Panggĕlaran, waarvan het begin reeds in 1887 door prof. Kern nitgegeven is in deze Bijdragen ( $5^{\mathrm{e}}$ volgr. II p. $581 \mathrm{sq}$ ). Daar prot. Kern aan zijn voornemen, om eene vertaling van den tekst te geveu, geen gevolg gegeven heeft, zal ik ook dit gedeelte van den Tantu, voor zoover het aan het Ādiparwa

1 Makolih heeft deze beteeketis ook in de 0. J. vert. van 't Mahabh. p. 16: Makolih ikang kuṇạala. Ādip. 83 beteekent het «ving (een visch).» Molih «in het bezit zijn van» komt o. a. voor Ādip. 52: molih mângsa. Evenzoo Ādip. 86: Moliha dharmmaswâmî “Mogen (zij) wettige echtgenooten erlangen.»

2 Met dezen daemon wordt Ràhu bedoeld, wiens naam, in het N. Jav. overgegaan, luidt rahu (kala rahu, karawu), Bat. akkalau, Maleisch rahu, Day. raho, Balin. rahu, rawu, kala rawu, Tagalog laho

3 Awayawa (Skr.) ode leden, het lichaam» komt ook voor Ādip. a, 22, Wirâțap. 28 en Udyogap. 78. Beide HSS. lezen hier ten onrechte law a y a y a.

4 Angkĕn of ângkěn staat hier en ook Àdip. 37 voor nângkĕn atelkens, periodisch terugkeerende» $=\mathrm{N}$. J. peṇậk, dat o. a. voorkomt $\bar{A}$ dip. 78: nângkěn Soma. Ādip. 79 : nângkěn tahun (elk jaar). Ādip 86 : nângkěn tilěm (elke nacht).

5 Parwakala (Skr.) atijd van conjunctie en oppositie», past in het zinsverband beter dan pùrṇakâla, zooals A of pùrṇamââla, zooals B leest, want deze beide woorden beteekenen «volle maan "

6 Amrta mangkana heb ik in amṛtamanthana veranderd, omdat dit gedeelte van den Skr. tekst (çl. 1094-1189) dezen naam draagt. 
ontleend is, vertalen. Het gedeelte dat ik op het oog heb, begint pag. 9 (van den overdruk) en luidt als volgt:

Wij zullen nu spreken over de goden, hoe zij hun eerbied betuigden aan Bhațâra Guru. Alle goden, de schaar der zieners, de nimfen, Widyâdhara's en Gandharwa's, allen verzamelden het stof van het voetenpaar van god Mahâkâraṇa. Nadat zij hun eerbied betuigd hadden, gingen zij allen op een rij zitten en makten hunne opwachting bij Bhațâra Guru. De god sprak: "O gij goden, gij allen, zienerschaar, nimfen, Widyâdhara's en Gandharwa's, gaat naar Jambudwîpa, mijne kinderen, gij allen. Vervoert ${ }^{1}$ den heiligen Mahâmeru, brengt hem naar het eiland Java, om ter bevestiging te strekken, opdat ${ }^{2}$ het vast sta en ophoude heen en weer te schudden ${ }^{3}$, het eiland Java; laat vooral de heilige berg Mandara hier komen; gaat ${ }^{4}$, mijne kinderen, alle!" Zoo sprak Bhațâra tot alle goden en de zienerschaar, de Widyâdhara's, Gandharwa's en nimfen. Zij allen gaven hem gehoor; zij vroegen verlof, om te gaan naar Jambudwîna en den heiligen Mandara geramenliik te verveneren Zij kwamen bij den berg van Jambudwîpa, die groot en hoog was en tot aan den hemel reikte; zijne hoogte was honderdduizend yojana's. Daar de afstand tusschen den hemel en de aarde honderdduizend yojana's bedraagt, was de heilige Mahâmeru vroeger honderdduizend yojana's hoog. Hij werd overgebracht naar het eiland Java, maar de helft bleef achter in Jambudwîpa. Daarom is de hoogte van den heiligen Mahâmeru nu tot de helft van den hemel. Dit nu is het ondereinde van den heiligen Mahâmeru, maar zijn top werd overgebracht naar Java. Deze nu werd door alle goden gezamenlijk gedragen. God Wiṣnu veranderde zich in een slang, die oneindig lang en groot was, en hij strekte tot touw bij het draaien van den

1 Alihakna heeft hier blijkbaar deze beteekenis. Het beteekent "worde toegewend» in Àdip. 121: Alihakna talinga pangrěngö. Zoo ook Ādip. 127 en 136.

${ }^{2} \mathrm{M}$ arapwan beteekent «opdat», bv. Ādip. 35 en 65 , Udyogap. a, 74 en a, 80, of «dan zal» bv. Àdip. 77 en Ram. 150. Ook «zoodat», bijv. Àdip. 71 en Swargârohapap. 97.



3 Enggang-enggung beteekent klaarblijkelijk hetzelfde als N. Jav. ஜ

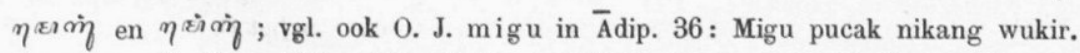
Kegù wordt Râm. 333 verklaard door het Balin. kahoyag. Het komt ook voor Ādip. 55: Kegù tekang pṛthiwi. Als een synoniem komt in het begin van den Tantu en ook in het vervolg het woord ma ray ěgan voor. Dit is verwant met het N. Jav. reyog en het 0 . Jav. uyag, dat voorkomt $\bar{A}$ dip. 49: Moyagan iki çarłranya.

${ }^{4} \mathrm{Laku}$ is hier als Imperat. van l umaku gebruikt. Zie prof. Kern's verhandeling over eenig imperatiefvormen van het Oudjavaansch (B. T. L. V. 1889, p. 22). 
heiligen Mahâmeru. God Brahmâ veranderde zich in een schildpad, die oneindig groot was, en hij strekte tot fundament bij het draaien van den heiligen Mahâmeru. Fluks wikkelde zich de slang om den heiligen Mahâmeru. Tegelijk liepen allen er schuins tegen op, om den heiligen Mahâmeru los te breken. Er kwam een groote glans uit, met donder en storm. Fluks ${ }^{1}$ gingen alle goden aan het werk; de zienerschaar gaf luide zijn bijval te kennen door lofliederen. God Wâyu, de krachtige god, zette zich fluks of den rug ${ }^{2}$ van den schildpaddenvorst. De heilige berg Mandara werd gedraaid door alle goden, die luide lofliederen aanhieven bij het vervoeren van den heiligen Mahâmeru. De bewoners van Jambudwîpa nu zagen hoe de heilige Mahâmeru naar $\mathrm{J}_{\mathrm{ava}}$ begon te gaan, maar de goden waren niet zichtbaar voor hen. Dit nu was de reden, dat zij een luid gerucht maakten, terwijl alle Brahmanen den heiligen berg Mandara verheerlijkten: jag pe rât lěs. Zoo luidden de lofliederen der Brahmanen.

Wij zullen nu spreken over alle goden, zij werden vermoeid door het draaien van den heiligen berg Mandara. Toen nu kregen zij dorst ${ }^{3}$. $\mathrm{Nu}$ was er water, dat uit den heiligen Mahâmeru kwam, vergiftig water, Kâlakûța genaamd. Dit nu was het vet van den berg. Daar alle goden vermoeid waren, slurpten ${ }^{4}$ zij het vergiftige water Kâlakûța op. Dadelijk stierven alle goden door de kracht van het vergiftige water, Kâlakûța genaamd. Dit zag god Parameçwara: "Hoe! Zijt gij dood, goden? Wat toch is de reden, dat gij allen dood zijt? Misschien hebben zij het vocht van den berg gedronken. Daardoor zijn zij allen gestorven. Kom, laat ik het opslurpen." Hij slurpte het water Kâlakutta op. De hals van Bhațâra werd zwart, alsof het een moedervlek was. Daarom wordt Bhațâra Guru Nîlakanțha ${ }^{5}$ ge-

$1 \mathrm{Jag}$ lěs. Over deze beide interjecties heb ik reeds in mijn Proefschrift (p. 177) gesproken. Dr. van der Tuuk deelde mij mede, dat in zijn HS. van het Acramaparwa, dat veel beter is dan het door mij uitgegevene Leidsche HS., de woorden (jag lis upapěr niet te vinden zijn, ook niet in de andere parwa's.» Dit laatste had ik zelf ook opgemerkt.

2 Tunggir beteekent in het Sundan. "staartbeen», in het Balin. "rugvinnen van een visch.» Hier beteekent het "rug »; vgl. ook Jav. pinggir en těnggěr.

3 Malapâ wai beteekent eigenlijk: (zij) kregen honger (gebrek) aan water. Wai, dat met air (e r) het gewone woord voor "water» in het 0 . J. is, is verwant met Fidji wai, Sumb. wâi, Bug. uwáe enz. (Kern, Fidjit. p. 196).

4 Tahap is verwant met Day. ihop, Jav aquz 29 Bul. Pak. Sea ělĕp, Bat. idup. Zie Brandes, Proefschrift pag. 99.

5 Nilakantha (Skr.) beteekent «blauwhals.n Het verhaal van het ontstaan van dezen bijnaam van Çiwa is ontleend aan het $\bar{A}$ diparwa. Men kan zelfs zeggen, dat de woorden van den Tą̧tu «matangnya bhațâra Guru mangaran 
noemd, omdat hij zoo zwart was als een moedervlek. Bhațâra Guru nu sprak: "Gij zijt werkelijk zeer krachtig! Ik ben door u bezeerd." Fluks keek hij naar het vergiftige water Kâlakûța. Dit nu kreeg de hoedanigheid van nectar, heilzaam water. Dit werd gebruikt, om den heiligen Kamanḍalu er mede te vullen, ten einde al de goden te besprenkelen. Fluks sprenkelde hij den heiligen nectar over alle goden. Zij nu werden weder levend, evenzoo de vier wereldhoeders, de Widyâdhara's en de Gandharwa's; alle goden betuigden hun eerbied aan Bhațâra Guru. Fluks sprak god Parameçwara: "Draait weder den heiligen berg Maudara. Laat hij naar Java komen! Vooruit, kinderen!" Zoo sprak Bhaṭâra tot alle goden. Zij allen gaven hem gehoor. Alle Daitya's, Dânawa's en Râkṣasa's werden aan het werk gezet (?) ${ }^{1}$; alle goden keerden terug; de heilige berg Mandara werd gedraaid. Fluks kwam hij op het eiland Java, aan de Westpunt. Daar stond de heilige Mahâmeru, sierlijk en flikkerend, een steunpunt voor de goden. Daarom werd de heilige Mahâmeru de berg Kailâsa genoemd, omdat hij ftikkerde ${ }^{2}$ en een steunpunt voor de goden was; het Westen van het eiland Java was laag, maar het Oosten hoog. De heilige Mahâmeru nu werd losgebroken en overgebracht naar het Oosten; zijn voet bleef achter in het Westen. Daarom was de berg, die nu Kailâsa heet, vroeger de voet van den heiligen Mahâmeru, naar men zegt. Zijn top werd overgebracht naar het Oosten. Hij werd gedraaid door alle goden gezamenlijk; toen stortte de heilige Mahâmeru ineen. Het eerste (stuk) van de gevallene aarde werd de berg Katong, het tweede van de gevallene aarde werd de berg Wilis; het derde van de gevallene aarde werd de berg Kâmpud; het vierde ran de gevallene aarde werd de Kawi; het vijfde van de gevallene aarde werd de berg Arjuna; het zesde van de gevallene aarde werd de berg Kumukus, een grot op zijde onderaan, ontstaan door het instorten van den heiligen Mahâmeru. Hij

Bhațâra Nilakaṇthan eene vertaling zijn van çloka 1154 b van den Sanskrittekst van het Ádiparwa, die luidt: Tadâ prabhṛti dewas tu Nılakaṇţha iti çrutih. In de 0 lav. vertaling komt deze passage toevalliger wijze niet voor, maar wel in de Manik Maya (Verh. Bat. Gen. XXIV p. us I, 34). De verklaring, die daar van Nilakantha gegeven wordt, is onjuist, zooals Winter reeds opgemerkt heeft in Tijdschr v. Ned. Indië, V, 1 p. 13 noot 3.

1 Inawesa schijnt hier deze beteekenis te hebben of die van «uitgenoodigd». Elders beteekent het "bezield» (Skr. âwișța), bijv. Ádip. 129: Kâweșa ta sira dening râksasa. Wirâtap. a, 17 komt de vorm angâweșa voor in de beteekenis "bezielen.»

${ }^{2}$ De verklaring van den Indischenen eigennaam Kailâsa uit het 0 . Jav. Inakelahkelah is natuurlijk ongerijmd. 
helde over 1 naar het Noorden in zijn stand en zijn top kwam in beweging ${ }^{2}$ en was gebroken. Toen nu zetten de goden den top van den heiligen Mahâmeru overeind "O heilige" zeiden alle goden. Daarom heet nu de top van den heiligen Mahâıneru Pawitra, volgens het oude verhaal. Maar de Mahâmeru stond niet vast; eindelijk leunde ${ }^{3}$ hịj tegen den berg Brahmâ. Blijkbaar zou de heilige Mahâmeru gevallen zijn, als hij niet geleund had tegen den berg Brahmâ, want hij was hol aan de onderzijde. De reden, dat hij vaststond, was de berg Brahmâ. Daarop stond de heilige berg Mandara vast. Daardoor was het eiland Java vast en hield het op, zich te bewegen en te waggelen. Nișadha beteekent "vast", daarom nu werd de heilige Mahâmeru de berg Niṣadha genoemd.

Daarop nu beval god Parameçwara aan alle goden, den heiligen berg Mandara te prijzen, om den inhoud van den heiligen Mahâmeru te verkrijgen. Vervolgens kregen de drie gezamenlijke goden ter belooning rijdieren: de witte stier werd het rijdier van god Içwara, de witte gans werd het rịjdier van god Brahmâ, de vogel Garuḍa werd het rijdier van god Wiṣnu *. Nadat de drie gezamenlijke goden tot belooning rijdieren gekregen hadden, prezen alle goden gezamenlijk deu heiligen Mahâmeru, den vorst der bergen. Dit is nu zoo gesteld. Er was een juweelen kruik, de heilige Kamaṇdalu genaamd, gevuld met den heiligen nectar, het heilbrengende water, die de kern van den heiligen berg Mandara was. Deze werd geprezen door alle goden. Nadat hij geprezen was, werd de kern van den heiligen Mahtımeru genomen, nl. robijnen, karbonkels en diamanten; deze werden aangeboden aan god Parameçwara; de heilige Kamandalu was onbekend. Fluks gingen alle goden weg, maar de heilige juweelen kruik bleef achter.

${ }^{1}$ Co ndo ong heeft deze beteekenis niet meer in het N. Jav. maar nog wel in het Mal. en Sundaneesch.

${ }^{2}$ Mol a h beteekent abewoog zich, trilden, bijv. Adip. 44: Sphurat 1 o c a na c a ñ ca la h, molah tânakan i[ng] mata nira. Ạ́̂ramap. a, 23 (pag. 58 van mijn Proefschrift): Ndatan molah sira. Zie ook Udyogap. 94.

3 S a nd a is verwant met Sund. sa nḍa, Mal. sandar, N. Jav. señ de. In A çramap. 5 is het eene vertaling van Skr. w y a pâçritya. Zie mijn Proefschrift p. 37 (fol. 5), p. 57 (fol. 22), p. 75 (fol. a , 41) en de aanteekening p. 160-161.

4 In het Àdip. çl. 1189-1545, overeenkomende met fol. 38 - 48 (van HS. B) wordt verhaald, hoe Wispnu Garuḍa tot rijdier nam wegens zijne dapperheid in den strijd tegen de goden. Prof. Kern leest hier Gar uḍadwija voor Garuḍadwaja. Misschien is echter dit woord te verklaren uit A dip. 40 (HS. A): Ndak palaku kita wâhanangku, lâwan tulisakna ri dhwajataṇangkwa. Deze woorden spreekt Wișu tot Garuḍa. Zie ook mijn Proefschrift p. 6-7. 
Er waren twee Râkșasa's, Râtmaja en Râtmajî genaamd; zij vermaakten zich op den berg Mandara, zij wilden goud, robijnen, karbonkels en diamanten verkrijgen naar hunne meening, maar zij troffen geen goud, robijnen, karbonkels en diamanten aan. Zij vonden den heiligen Kamanḍalu en namen hem van 1 zijne plants, zij meenden dat hij diende om er zich mede te vermaken, niet wetende, wat het nut er van was; hij zag er werkelijk blinkend uit, daarom noemden zij den heiligen Kamaṇḍalu Sang Hyang Ktĕk Mĕlĕng. Fluks gingen Râtmaja en Râtmajî weg.

Wij zullen nu spreken over alle goden, hoe zij Bhațâra Guru hun eerbied kwamen betuigen. Bhațâra sprak: "Mijne kinderen, goden! Waar hebt gij de kern van den heiligen Mahâmeru gelaten, kinderen?" Zij boden hem het goud, de robijnen, karbonkels en diamanten aan. "De juweelen kruik, de heilige Kamaṇdalu, gevuld met den heiligen nectar, het heilbrengende water, waardoor alle goden in het leven teruggeroepen zijn, is er niet." ${ }^{2}$ Zoo sprak god Mahâkârana. Geen van de goden wist, wie den heiligen Kamaṇdalu genomen had, en ook de ziener Nârada, Kapila, Ketu, Tumburu, Sthâpaka ${ }^{3}$ en Wiçwakarmmâ wisten niet, wie den heiligen Kamand̦alu weggekaapt had. De vier wereldhoeders: Indra, Yama, Waruṇa en Kuwera, de zienerschaar, de nimfen, Widyâdhara's en Gandharwa's wisten het evenmin. Alle goden waren in verlegenheid. Ten slotte werden de Zon en de Maan ondervraagd door de goden. De Zon sprak: "Er zijn twee Râkșasa's, Râtmaja en Râtmajî genaamd; deze hebben den heiligen Kamaṇḍalu genomen.” Zoo spraken de Zon en de Maan. God Brahmâ en Wiṣnu nu gingen naar de plaats, waar zich Râtmaja en Râtmajî bevonden. Fluks kwamen zij bij de Râkșasa's. Râtmaja en Râtmajî zeiden: "Het is vreemd, dat de goden hier komen. Wat is het doel van uwe komst?" Brahmâ en Wiṣnu zeiden: "Het doel van onze 4 komst is te vragen, wat gij gekregen hebt uit den berg Mandara?" De

1 Iring en iri = ring en ri. Zie mijn Proefschrift pag. 162.

2 Prof. Kern vermoedt, dat hier de woorden "ndi ta sang hyang kamañalu» of iets dergelijks weggevallen zijn. In dat geval zou men $\mathrm{tan} h$ a $\mathrm{n}$ a in den vorigen zin moeten vertalen door «was er niet.» Volgens mijne meening bevat echter juist de vorige zin de woorden van Civiva tot de goden.

${ }^{3}$ Bij dezen eigennaam teekent prof. Kern aan, dat mogelijk ook $\mathrm{S}$ thap a ti gelezen moet worde. Het HS. heeft saptaka. De ziener Tumburu komt ook voor Manik Maya I, 51 (Verh. Bat. Gen. XXIV p. us), overeenkomende met pag. 19 van Winter's vertaling (Tijdschr. v. Ned. Indië V, 1).

${ }^{4}$ Pwangkulun beteekent «ik, wij.॰ Zie mijn Proefschrift pag. 198. 
Râkșasa 's antwoordden : "Wij hebben geen goud, robijnen, karbonkels of diamanten gevonden. goden. Maar wij hebben Ktĕk Mlĕng gekregen." De goden antwoordden: "Wat noemt gij Ktěk Mlĕng? Hoe ziet het er uit?" Zij lieten de juweelen kruik zien. Daarop begeerden de goden haar. Maar de Râkșasa's wilden haar niet geven. Zij wenschten haar te koopen voor goud en juweelen. De Râkșasa's gaven haar niet. Ten slotte vroegen de Râkșasa 's: Waartoe dient de juweelen kruik?" De goden zeiden: "Deze juweelen kruik heet de heilige Kamandalu en is gevuld met den heiligen nectar, het heilbrengende water, dat de goden heeft doen herleven." Fluks namen de Râkșasa's de juweelen kruik. Daarop bewaakten ${ }^{1}$ zij beiden haar. Toen waren god Wiṣnu en Brahmâ beschaamd. Op verzoek van god Brahmâ aan Wiṣnu, om zich in te spannen, nam deze de gedaante van eene schoone vrouw aan. Zoo was nu zijn uiterlijk. Hij kwam op de plaats, waar Râtmaja en Râtmajî zich bevonden. Hij verzocht de juweelen kruik. Daarop sprak hij hen vleiend toe. De Râkșasa's waren verrakt toen zij de schoone vrouw zagen. Daarop gaven zij haar de juweelen kruik, die god Wiṣnu vasthield. Fluks liepen Brahınâ en Wiṣnu er mede weg. Râtmaja en Râtmajî vervolgden hen, maar zij konden Brahmâ en Wiṣnu niet inhalen, omdat zij uiterst snel liepen. Râtmaja en Râtmajî waren beschaamd.

Ten slotte wijs ik nog op het overeenkomstige gedeelte van den Manik Maya, I, 24-II, 27 (p. ฉภ-p. ån aภ van de Hollander's edit. in Verh. Batav. Gen. XXIV, 13). Daar dit gedeelte door Winter vertaald is in het Tijdschr. v. Ned. Indië ( $\mathrm{V}, 1 \mathrm{p} 10-25)$ en ook gedeeltelijk reeds vroeger door Lipjes in hetzelfde tijdschrift (III, I p. 67-68), zal ik er hier niet veel over zeggen. De eigennamen zijn hier nog meer verbasterd dan in den Tantu en een gedeelte (II, 16-21, overeenkomende met p. 23 van de vertaling) is later ingevoegd, daar hier sprake is van Allah 2 .

${ }^{2} \mathrm{~K}$ e m it heeft hier blijkbaar eene ruimere beteekenis dan in het N. Jav. waar het alleen "nachtwacht» beteekent. Dit blijkt ook uit de 0 . Jav. vertaling van 't Mahâbh. p. 14: Akmita ri sang gurupatni. Zoo ook Ādip. 46: Kârananya tkâ ring sthâna kiněmit (bewaakt). Ādip. 87: Wineh ta sirâkmitanâlalang. Ādip.94: kmitěn pahayun "(mijn) wensch (is), dat het bewaard worde.» De vorm k ěmitan komt voor Wirâtap. a, 13. M a ng ěmit wordt Râm. 61 verklaard door het Bal. mangraksa. VgI. ook Mak. ka mi.

1 Reeds Winter heeft (in Tijdsch. v. Ned. Indië, V, 1 p. 23 noot) opgemerkt, dat deze passage geen bewijs is van een lateren oorsprong van den Manik Maya. 
Gaan wij thans eens na, in welke opzichten het $\overline{\text { Adiparwa, de }}$ Tantu en 'de Manik Maya overeenstemmen. Het verhaal van het vervoeren van den Mahâmeru naar Java is op zich zelf niet ontleend aan het Adiparwa, maar het is verward met de geschiedenis van het karnen van de Melkzee, waarbị de Mandara als karnstok diende. Ook zijn de beide bergnamen Mandara en Mahâmeru in den Tantu telkens verwisseld. In den Manik Maya wordt alleen verhaald, dat de berg Jamur Dipa van Westjava naar Oostjava overgebracht wordt. In het A diparwa wordt de hoogte van den Mandara als elfduizend, in den Tantu als honderdduizend yojana's opgegeven. Ook is in het Ādiparwa Wiṣnu als schildpad het fundament en Wâsuki het touw, terwịl in den Tantu Brahmâ de functie van Wiṣnu en Wiṣnu die van Wâsuki vervult. In den Manik Maya is Brahmâ het draagzeel, Wâyu de draagstok en Indra het touw ( $\mathrm{I}, 31-32$, pag. 12-13 van de vertaling). De geschiedenis, hoe de goden sterven door het vergiftige water te drinken, komt zoowel in den Tantu als in den Manik Maya voor, maar de echte naam Kâlakûța is in den Manik Maya verbasterd tot Cala Kuṭa (I, 35, pag. 14. van de vertaling). Dat Çiwa bịj deze gelegenheid den bijnaam Nîlakanțha kreeg is eene bijzonderbeid, die de Tantu en Manik Maya rechtstreeks aan het - $\mathbf{a}$ diparwa (çloka 1154 van den Skr. tekst) ontleend hebben, hoewel de O. Jav. vertaling deze passage mist. De verklaring van den Indischen eigennaam Kailâsa uit het O. Jav. makelah "flikkeren" in den Tantu is ten eenenmale ongerijmd. In den Tantu heeten de bergen, die ontstaan uit de van den Mahâmeru afgevallene aarde: Katong, Wilis, Kâmpud, Kawi, Arjuna en Kumukus; in den Manik Maya: Tĕmpora, Wala Hulu, Ci Rĕbah, Pragota, Kẹṇ̣eng, Sumbing en Séndara 1 ( $\mathrm{I}, 42-44$, pag. 15- I6 van de vertaling). Daarop volgt in den Manik Maya een gevecht tusschen Ĺmpu Ramadi en Wayu, dat eene horinnering schịjut te zịjn aan den strijd tusschen de goden en dânawa's in het - Adiparwa. In den Tantu zịjn de dânawa's vertegenwoordigd door de beide râkṣasa's Râtmajî en Râtınaja, die zich meester maken van den Kamanḍalu, evenals de dânawa's in het Ádiparwa. De list, waardoor Wiṣnu in den Tantu den nectar terugneemt, is dezelfde als die in het a diparwa, maar vooraf wordt in den Tantu verhaald, dat de Zou en de Maan hem gewaarschuwd hadden, dat Râtmaja en Râtmajî den Kamandạalu hadden. In het Adiparwa waarschuwen de Kon en Maan Wịnnu, dat Râhu van

1 Evenzoo in de Sundan. prozabewerking, uitgegeven door Vir. G. J. Grashuis (Soendaneesch leesboek, Leiden 1874 p. 122-123). 
den nectar gedronken heeft, zoodat Râtrraja en Râtmajî in den Tantu eerst de functie van Râhu, daarna die van de danâwa's in het Ádiparwa vervullen. Het verhaal van het ontstaan van de eclipsen, doordat een monster zon en maan verslindt, komt in den Manik Maya voor en is waarschijnlijk aan het $\bar{A}$ diparwa ontleend. Alleen heet Râhu in den Manik Maya Rĕmbu Culung (II, 22, pag. 24 van de vertaling) en later Karawu (II, 26 pag. 25 vert.). Dit verhaal is daarom belangrijk, omdat het niet alleen bịj de tegenwoordige Javanen, maar ook bij de Bataks 1 en Dayaks ${ }^{2}$ bekend is. Bij de Bataks heet de booze geest, die de eclipsen veroorzaakt, akkalau = Skr. kâla Râhu, bij de Maleiers rahu, bij de Dayaks raho. Bij deze drie volken schịnt die voorstelling aan het Ádiparwa (1161-1166 van den Skr. tekst, overeenkomende met fol. a, 37 van de O. Jav. vertaling of andere Indische bronnen ontleerd te zijn. Intusschen heeft prof. Wilken ${ }^{3}$ reeds opgemerkt, dat eene dergelịke verklaring van eclipsen ook bij de Bolaäng Mongondouers en de Alfoeren van Halmahera, ja zelfs bị de volken, die de eilanden van de Zuidzee bewonen, voorkomt. In elk geval blijkt uit het bovenstaande duidelijk, welk een invloed het Mahâbhârata op de mythologische en cosmologische begrippen der Javanen uitgeoefend heeft. De invloed van het Indische epos op het Javaansche epos Bratayuda en op de Javaansche lakons is reeds vroeger aangetoond door Cohen Stuart in zijne inleiding van het Bratayuda en door prof. Kern in zijne verhandeling "eene Indische sage in Javaansch gewaad." De Obongobongan bale si Galagala is blijkbaar aan het Jatugrhaparwa van het Adiparwa ontleend, maar het slot is eene herinnering aan het Wirâțaparwa, zooals ik reeds in mijn Proefschrift (pag. 11) gezegd heb. De geschiedenis van den dood der Pânḍawa's en hnnne herleving, die onmiddellijk daaraan voorfgaat (Eeue Indische sage etc. p. 21-22) is ontleend an het A raneyaparwwa van het Wanaparwa (ed. Calc. I, p. 823), waarop gezinspeeld wordt in Prasthânikaparwa a. $54^{4}$. Uit dit alles ziet men genoegzaam, van welk belang eene nauwnauwkeurige lezing van het Mahâblârata is, daar het de hoofdbron van de epische, dramatische en mythologische letterkunde der Javanen kan genoemd worden.

1 Niemann in Tijdschr. v. Nederl. Indië, jaarg. 1870, I p. 292.

2 Hupe in Tijdschr. v. Nederl. Indië, jaarg. 1846, III p. 157.

3 Animisme, pag. 254-256.

${ }^{4}$ Zie mijn Proefschrift, p. 88, p. 145 en p. $215-216$. 


\section{N A S C H R I F T.}

Ook in het O. Jav. Râmâyana wordt op twee plaatsen gezinspeeld op het verhaal, waarover dit opstel handelt, n.l. fol. 29: Kṣ̂rodasâgara nahan pinutěrta ngûni, mwang Râhu yekana cinakra gulûnya denta. Dit vertaalt de Balineesche glossator door: Lawanasâgarane punika putěr i dewane sâmpun, smalih Kalarahune punika i dewa mañakra bahongane. Ook in fol. 24] dient dit verhaal tot eene zeer uitgewerkie vergelijking, die aldus begint:

Sphațikaprasâda kadi Mandara yâ, ikanang natar kadi tasik susu yâ, maṇi mutya yekana kadi pwa wĕröh, wway atomatis ya amrrtanya mtu, enz. De Balineesche vertaling luidt: I candimanik sphați mahirib gunung Mandara, punika natahñane mahirib susu ning pasih ${ }^{1}$, malih i mutehara punika ya kasěngguhang didih, ika yehñane tis punika udakañane mijil, enz.

1 Dit is natuurlijk eene onjuiste vertaling van het 0 . Jav. tasik s u s u, waarmede de schrijver van het Râmâyaṇa het Skr. Ksîrasâgara of Ksirasamudra weergeeft. 